\title{
Maze companion: aplicativo de inteligencia artificial que ayuda a solucionar laberintos ${ }^{*}$
}

\author{
Yana Saint-Priest Velásquez* \\ Oscar Domínguez Acevedo ${ }^{* *}$ \\ Carlos Márquez Hernández ${ }^{* * * *}$
}

Recibido: 22/10/2018 - Aceptado: 28/06/2019

https://doi.org/10.22395/rium.v19n36a5

\begin{abstract}
Resumen
La capacidad de concentración de un niño depende de su edad y lo normal es que a medida que crece, aumenta este tiempo de atención; sin embargo, es importante trabajar esta capacidad desde edades tempranas. Los clásicos juegos de mesa como ajedrez, laberintos, triqui, rompecabezas, etc., requieren cierta cantidad de procesos mentales para ser jugados y son ideales para mantener la atención del niño durante varios minutos. El presente proyecto es una propuesta innovadora a través del procesamiento de imágenes y algoritmos de búsqueda por anchura, resuelve laberintos físicos creados por los jugadores. La efectividad obtenida fue de un $72 \%$, se recalca que la calidad del sensor y el ángulo en el cual se toma la fotografía influyen enormemente.
\end{abstract}

Palabras clave: acompañante de juego; inteligencia artificial; laberinto; procesamiento imágenes.

Artículo resultado de una investigación terminada Aplicación del procesamiento de imágenes y la inteligencia artificial en solución de juegos didácticos, ejecutada entre febrero y diciembre de 2017 y, financiada por la Universidad Santiago de Cali, Colombia.

** Ingeniera de Sistemas de la Universidad del Norte. Magíster de la Universidad de los Andes con Especialización en Evaluación en Entornos Virtuales, de la Universidad de Granada. Actualmente docente de la Universidad Santiago de Cali, Calle 5 \# 66-00, y miembro del Grupo de Investigación en Ingeniería Electrónica, Industrial y Ambiental. (Gieiam). Correo electrónico: yana.saint-priest00@usc.edu.co. Orcid: http://orcid.org/0000-0002-2998-6497

*** Técnico en Programación de Software del Sena, Tecnólogo en Sistemas de Información e Ingeniero de Sistemas de la Universidad Santiago de Cali. Actualmente labora en Mydigitall, Carrera 67 \# 11B-12, Cali, Colombia. Miembro del Grupo de Investigación Comba. Correo electrónico: oscardominguez93@hotmail.com. Orcid: https://orcid.org/0000-0002-9488-3726

***** Tecnólogo en Sistemas de Información e Ingeniero de Sistemas de la Universidad Santiago de Cali. Actualmente labora en Colgate Palmolive, Carrera 1 \# 40-108, Cali, Colombia. Miembro del Grupo de Investigación Comba. Correo electrónico: karlosmqz@gmail.com. Orcid: https://orcid.org/0000-0002-8490-540X 


\title{
Maze companion: artificial intelligence application that supports mazes solving
}

\begin{abstract}
The concentration capabilities of a child depend on his or her age and the normal process is that along with their growth their attention span grows as well; nonetheless, it is important to work on this capability from a young age. The classic board games such as chess, mazes, triqui, puzzles, etc. require a certain amount of mental processes in order to be played and are ideal for keeping the attention of the child for several minutes. This project is an innovative proposal through image processing and width search algorithms; it solves physical mazes created by the players. The obtained effectiveness was $72 \%$, remarking that the quality of the sensor and the angle in which the photograph is captured is of enormous influence.
\end{abstract}

Keywords: game companion; artificial intelligence; maze; image processing.

\section{Maze companion: aplicativo inteligência artificial que ajuda a resolver labirintos}

\begin{abstract}
Resumo
A capacidade de concentração de uma criança depende de sua idade. Em geral, à medida que crescem, aumenta-se esse tipo de atenção; contudo, é importante trabalhar essa capacidade desde cedo. Os clássicos jogos de mesa como xadrez, labirintos, jogo da velha, quebra-cabeça etc. requerem processos mentais para serem jogados e são ideais para manter a atenção da criança durante vários minutos. Este projeto é uma proposta inovadora por meio do processamento de imagens e algoritmos da busca em largura, resolve labirintos físicos criados pelos jogadores. A efetividade obtida foi de $72 \%$, salientando que a qualidade do sensor e o ângulo no qual se toma a fotografia são de grande influência.
\end{abstract}

Palavras-chave: acompanhante de jogo; inteligência artificial; labirinto; processamento, imagens. 


\section{INTRODUCCIÓN}

Las características de falta de atención, hiperactividad o impulsividad son conductas propias de la infancia, puesto que es natural que los niños sean muy activos, presten poca atención y escuchen poco [1-2]. También suele haber muchos niños que tienen problemas con las matemáticas y otras dificultades más. Lo anterior puede ser tratado y mejorado practicando ciertos juegos, como resolver laberintos. Un laberinto es una herramienta ideal para que los niños vayan desarrollando algunas habilidades [3].

Por otro lado, los juegos de mesa han servido como psicoterapia para los niños pues mejoran sus necesidades defensivas, relaciones interpersonales y expresivas [4], también ofrecen mejoras en la educación brindando entretenimiento a los estudiantes y facilidades a los profesores en la comunicación y enseñanza [5]. Fomentan la memoria al tener que aprender las reglas y aplicarlas de la mejor manera [6], brindando muchos beneficios.

El desarrollo de laberintos por parte de los niños tiene grandes ventajas, como por ejemplo: fortalece su capacidad para prestar atención, también puede ser una buena herramienta de diagnóstico para ver qué tan rápido aprenden y son capaces de tomar decisiones, sin mencionar que es un instrumento ideal en el fomento de la persistencia. Después de resolver el laberinto el niño podrá apreciar si el camino escogido es el más rápido para llegar a la solución.

Según estudios, los niños pasan gran parte de su tiempo en actividades tecnológicas que no están bien enfocadas, ocasionando que no tengan tiempo para juegos de mesa o de interacción motriz [7].

Es cuando surge la pregunta ¿Es posible crear un juego físico que permita construir laberintos y una aplicación móvil que los resuelva, enfocando la atención del niño por más tiempo en una misma actividad?

La mayoría de los trabajos existentes se encuentran relacionados con robots resolviendo laberintos, tal es el caso de una investigación de la Escuela Colombiana Julio Garavito, que construyó un móvil capaz de salir de un laberinto según indicaciones enviadas por un computador, posterior al procesamiento de la imagen capturada por una cámara [8]. $\mathrm{O}$ un agente inteligente que usa procesamiento de imágenes y teoría de grafos y logra crear un solucionador de laberintos [9]. Sin embargo, también existen iniciativas en el área de software con aplicaciones lúdicas para niños, por ejemplo, Josué Osorio Flores creó un sistema llamado MAZE3D, un juego programado con el fin de crear aleatoriamente escenarios de mapas tridimensionales. Este juego le permite a un especialista realizar un estudio sobre la destreza del niño, teniendo en cuenta el tiempo de resolución de estos escenarios y el niño a su vez mejora la capacidad para 
resolver los diferentes escenarios. El programa fue probado con algunos usuarios (niños) y se obtuvo un promedio de 73,3\% de mejora, además se encontró que al 86,6 \% de usuarios les pareció interesante este juego de realidad virtual [10].

Juan Grompone, propone la implementación de nuevas tecnologías en la educación para construir diseños alternativos, con el fin de estudiar los diferentes comportamientos de niños y adolescentes en cuanto a la forma y velocidad que cada uno toma para alcanzar el objetivo del laberinto. El ejercicio consiste en entregar a cada niño y profesor una computadora donde tendrá el juego electrónico de un laberinto, esta metodología, afirma Grompone, es una herramienta educativa poderosa y eficaz que desarrolla en ellos nuevas habilidades [11].

Es así que se plantea la construcción de un aplicativo móvil de inteligencia artificial que a través del procesamiento de imágenes y un algoritmo de búsqueda por amplitud, permita acompañar e incentivar al desarrollo de actividades estratégicas como los juegos de mesa y juegos reales [12-13], ofreciendo beneficios como: ejercitar la mente, mejorar la concentración, la motricidad, incentivar el aprendizaje de matemáticas, beneficiar la memoria, mejorar los tiempos de respuesta, ayudar a reducir el estrés y la tensión [14-16].

\section{MATERIALES Y MÉTODOS}

El proyecto consiste en un tablero-laberinto físico y un aplicativo. El aplicativo extrae las características (fichas geométricas, entrada, salida, obstáculos y caminos con diferenciación de colores) para construir el modelo icónico actual del tablero del laberinto que se está jugando. En la figura 1 se puede observar la imagen análoga y el modelo ideal digitalizado.

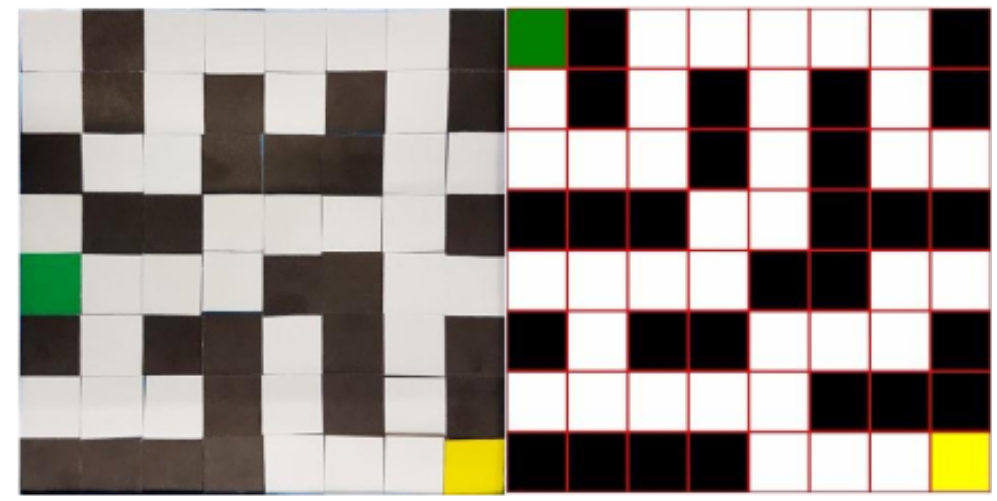

Figura 1. Imagen para procesar del laberinto en una captura análoga y la imagen digital en un entorno ideal de la solución Fuente: elaboración propia 
Posteriormente se aplicó el algoritmo de búsqueda por amplitud para seleccionar el camino que resuelve el laberinto. Se encuentra desarrollado en el lenguaje Java con la librería OpenCV, diseñado para desktop-web y emplea como sensor de entrada la cámara que se desee incorporar.

La figura 2 resume los principales pasos empleados por la aplicación para encontrar la solución. Posteriormente se detalla cada uno de ellos.

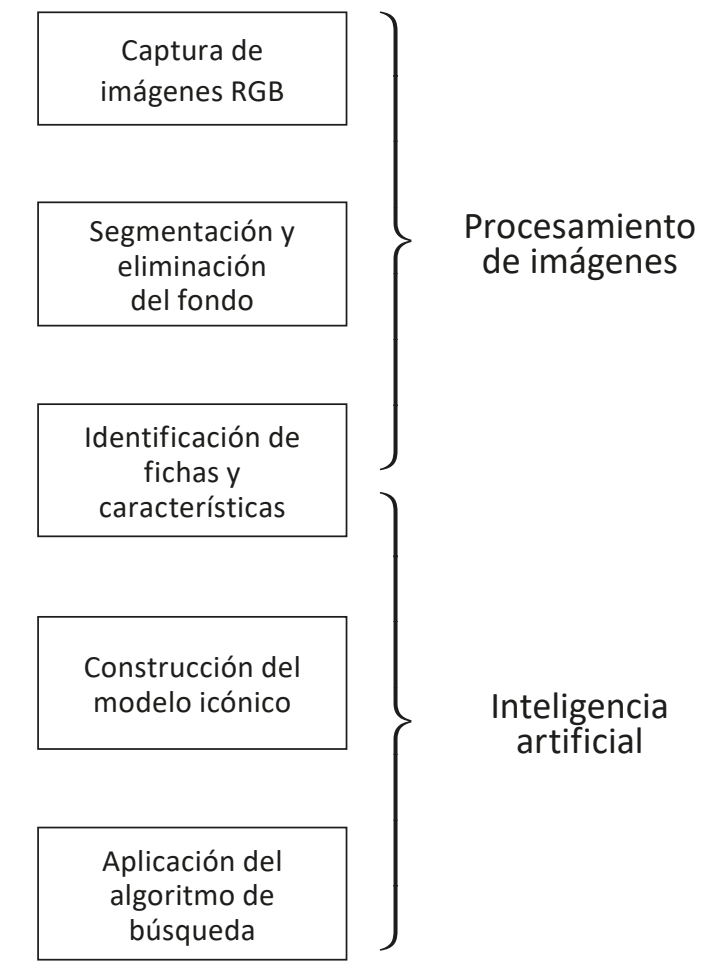

Figura 2. Secuencia algorítmica de pasos para la solución Fuente: elaboración propia

La cámara capta las imágenes del entorno y las guarda en la memoria desktop-web para ser evaluadas. Las imágenes son RGB. El primer paso consiste en seleccionar el segmento de la imagen que se desea evaluar, así tomar la fracción del tablero de juego del laberinto. Se delimita, se elimina el fondo y el elimina el ruido, se pasa a escala de grises tomando el área del tablero de juego, se divide el alto y el ancho de la imagen en ocho, que son los recuadros de las fichas del laberinto, con eso se conoce el tamaño de cada casilla. Posteriormente se divide en dos tomando el centro de esa ficha para evaluar qué color es (el umbral) para identificar si es una casilla de entrada, salida, obstáculo o camino y se pasa a una función de OpenCV que evalúa las fichas que componen el tablero. 
Consecutivamente se extraen las posiciones de las fichas evaluando los colores y creando la matriz con las fichas identificadas. Luego se desarrolla la segunda fase del procesamiento, cuyo objetivo es identificar el contenido del tablero de juego capturado y construir el modelo icónico que ingresa al algoritmo de búsqueda por amplitud de inteligencia artificial, previamente diseñado para evaluar las posibles soluciones de los caminos del juego actual.

El algoritmo de búsqueda por amplitud crea el árbol de búsqueda (un compuesto de nodos que almacena la información estructurada en un consecutivo de varios niveles de búsqueda) y verifica las posibilidades de qué camino seguir para llegar a la solución. La evaluación del algoritmo toma la decisión del camino a seguir para llegar a la salida del laberinto. En la figura 3 se indican las características del segmento a analizar.

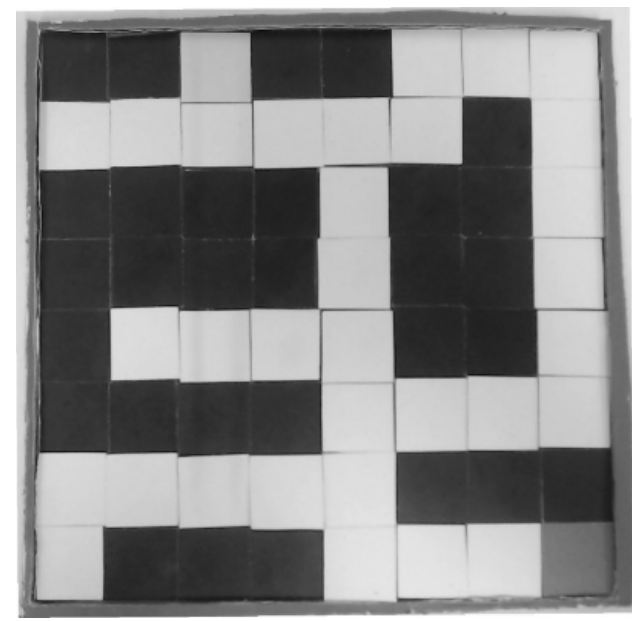

Figura 3. Imagen del segmento para el procesamiento del laberinto para su posterior solución Fuente: elaboración propia

\subsection{Entorno de desarrollo}

Para desarrollar este proyecto de investigación se utilizó la integración de dos grandes tecnologías: procesamiento de imágenes e inteligencia artificial. Lo anterior permite sacar el mayor provecho de algunas de sus técnicas para el cumplimiento de los objetivos definidos al comienzo.

\subsection{Procesamiento de imágenes}

\subsubsection{Procesamiento de imágenes digitales}

El procesamiento de imágenes y los patrones de reconocimiento están aplicados a una gran variedad de campos, incluyendo áreas de la medicina, alimentos y sensores [17]. 
Tiene como objetivo mejorar el aspecto de las imágenes y hacer más evidentes en ellas ciertos detalles que se desea resaltar [18]. En el proyecto se utilizaron técnicas de procesamiento de imágenes digitales que permitieron intervenir una fotografía para obtener el modelo icónico del tablero del juego. Con esta se creó una matriz y reconociendo de los colores de las fichas, identificando la salida, entrada, obstáculos y caminos del laberinto.

\subsubsection{Librería OpenCv}

Es un recurso abierto que permite iniciar en la visión computacional, innovar en el espacio de los algoritmos y métodos en los sistemas de visión computacional [19].

Es utilizada para procesar imágenes digitales de una forma rápida, ya que brinda herramientas y métodos para integrar sensores de los dispositivos [20]. El proyecto fue desarrollado en el lenguaje java, con las librerías que ofrece OpenCv para lograr el objetivo de tomar la información del modelo icónico [21].

\subsubsection{Modelo icónico}

Mecanismo de representación que permite a los agentes sacar partido de la información del entorno que no es percibida directamente. Este conocimiento puede consistir en información declarativa sobre el estado del entorno y modelos icónicos del entorno [21]. Es necesario que se represente la información del entorno que ha sido capturada por las técnicas de procesamiento de imágenes digitales por medio de modelos icónicos, así el agente podrá entender y resolver los problemas, como se observa en la figura 2.

Estos utilizan estructuras de datos y algoritmos para simular diferentes aspectos del entorno y efectos de las acciones del agente sobre ese entorno.

\subsection{Inteligencia artificial}

\subsubsection{Algoritmo de búsqueda por amplitud}

Este algoritmo es ideal para buscar un elemento en un grafo (conjunto de puntos conectados), intuitivamente inicia por la raíz y explora todos los vecinos de ese nodo. Para cada uno de los vecinos se exploran sus respectivos vecinos adyacentes y así hasta recorrerlos todos. Es un algoritmo usado para recorrer o buscar elementos en una estructura de datos como los árboles y los grafos, pertenece al grupo de los algoritmos de búsqueda sin información. Su procedimiento consiste en ir visitando todos los nodos de un nivel antes de proceder con el siguiente [21].

Es también conocido como BFS (breadth first search), pues expande y examina todos los nodos de un árbol sistemáticamente para buscar una solución. El algoritmo no usa ninguna estrategia heurística, en la figura 4 se observa su interpretación. 


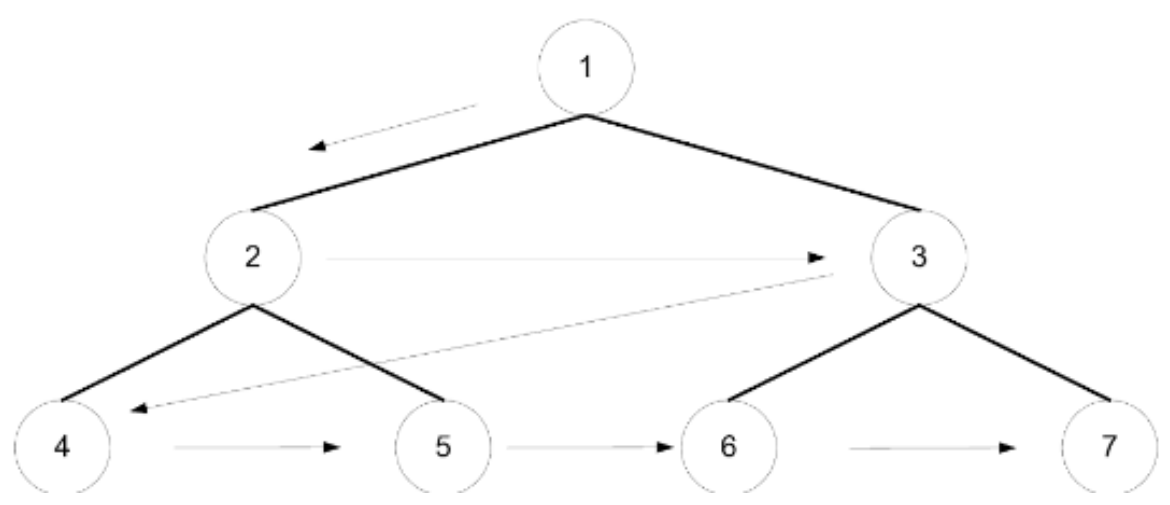

Figura 4. Algoritmo de búsqueda por amplitud Fuente: elaboración propia

En el proyecto, usar el algoritmo de búsqueda por amplitud ayuda a encontrar los caminos posibles para solucionar el laberinto. La función evalúa los caminos correctos para decidir por cuál ir, mirando el panorama completo del tablero en función de valorar los caminos futuros del laberinto.

\subsubsection{Aplicativo}

Es una aplicación de software que se adapta a los dispositivos a utilizar. Una aplicación es un programa que se puede descargar y acceder directamente desde cualquier desktop, smartphone, tableta y dispositivo inteligentes y que brinda una solución de herramientas al alcance de la mano [22].

Este proyecto es una aplicación que utiliza librerías OpenCv de reconocimiento de imágenes digitales para procesar la imagen, expresar el modelo icónico, crear la matriz del laberinto y permitir al agente ejecutar el algoritmo de búsqueda por amplitud que recorre el árbol del juego y da los posibles caminos para resolver el laberinto.

\section{RESULTADOS}

Al hacer la recolección de imágenes y su posterior reconocimiento, se encontraron diferentes inconvenientes que dificultaron la detección del laberinto. Uno de los escenarios más frecuentes fue descubrir que al tomar la captura de imagen con un ángulo diferente a $90^{\circ}$, se dificulta identificar las características correctamente por la presencia de zonas opacas, descoloridas, fondos que se confunden con el laberinto y reflejos de luz interpuestos en la imagen. Para solucionar estas situaciones en este primer prototipo, se trabajó con un entorno controlado, un borde azul adherido al laberinto y mejoraron las condiciones de luminosidad del entorno, ver figura 5. 


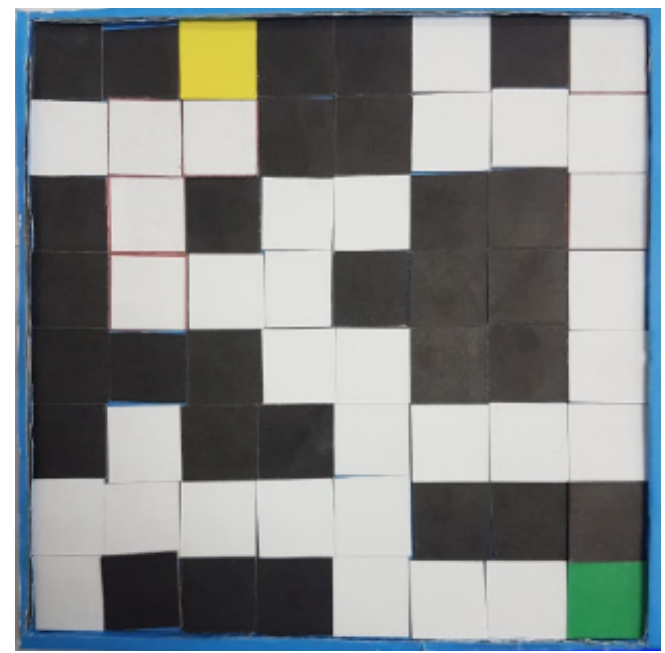

Figura 5. Imagen del laberinto con un reborde azul Fuente: elaboración propia

Al tener un tablero de juego que no es tan complejo, se puede crear un árbol de búsqueda completo en anchura, esto permite siempre encontrar la solución del laberinto, aunque no siempre es la más óptima, sino una de las soluciones del juego (si hay más de una).

Se optó por construir un árbol que no fuera tan extenso pero que cumpliera con todas las necesidades para la solución, al tener diferentes oportunidades de expandir la búsqueda, Considerando que este depende del número de obstáculos que se presenten en el escenario de juego.

Después del procedimiento que se ha llevado a cabo con la imagen, el sistema procede a identificar el modelo icónico, representado por una matriz de 8 x 8 con su respectivo vector de características el cual indica detalladamente a qué hace referencia cada una de las coordenadas. Si se trata de una entrada, se representa con una (I); un muro con una $(\mathrm{X})$; un camino con un ( ) espacio en blanco; un camino ya recorrido con un (.) y por último, un estado final u objetivo, se representa con una (S). Como se puede detallar en la figura 6.

Una vez sea reconocido el modelo icónico, el sistema procede a aplicar el mecanismo de planeación sin información, la búsqueda por anchura, empezando desde la casilla raíz en este caso entrada (I) y visitando cada casilla vecina. Se establece una pila doblemente enlazada (Linkedlist - permite eliminar y agregar elementos usando iteradores y acceder a ellos de forma secuencial) durante el proceso, añadiendo cada casilla y por medio del Linkedlist se realiza una búsqueda desde el punto de partida (I), marcando cada casilla del camino recorrido con un punto (.) o si se trata de un 
muro con una (X), así sucesivamente hasta encontrar la casilla correspondiente a la salida (S). En caso de existir otro camino que supla la necesidad de llegar al objetivo, el usuario puede observar cuál es el camino más corto. En la figura 7 se muestra la evaluación del laberinto y su camino para ser solucionado.

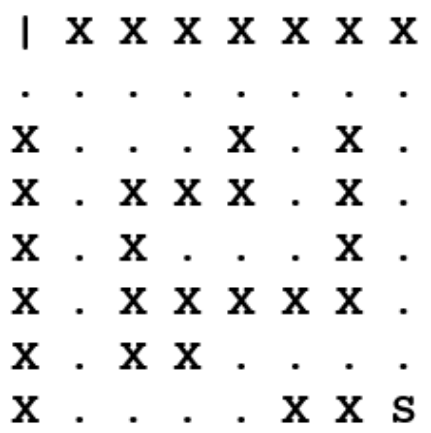

Figura 6. Imagen de la extracción de características y generación del modelo icónico Fuente: elaboración propia

\section{Camino:}

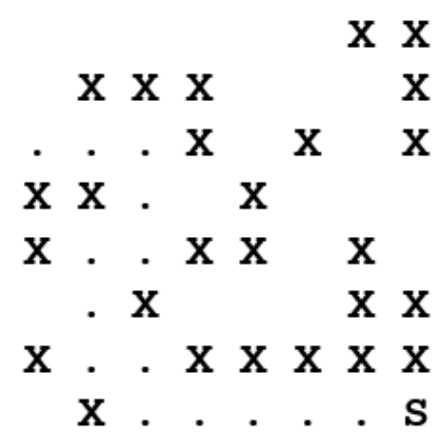

Figura 7. Imagen de la solución del laberinto, el camino trazado por los puntos a la salida Fuente: elaboración propia

Para probar el funcionamiento del aplicativo se realizaron mediciones con 100 imágenes tomadas en un área controlada. Se observan en la figura 9 varias tomas de imágenes del laberinto para su posterior análisis. Entre estas imágenes está el laberinto de juego a distancias de 45 y $60 \mathrm{~cm}$, basado en la resolución del dispositivo de captura de la imagen desde diferentes ángulos, imágenes oscuras, con poca luminosidad, desenfocadas, con el reflejo del sol, con el reflejo de luces en las muestras de la investigación, etc., (ver figura 8). 


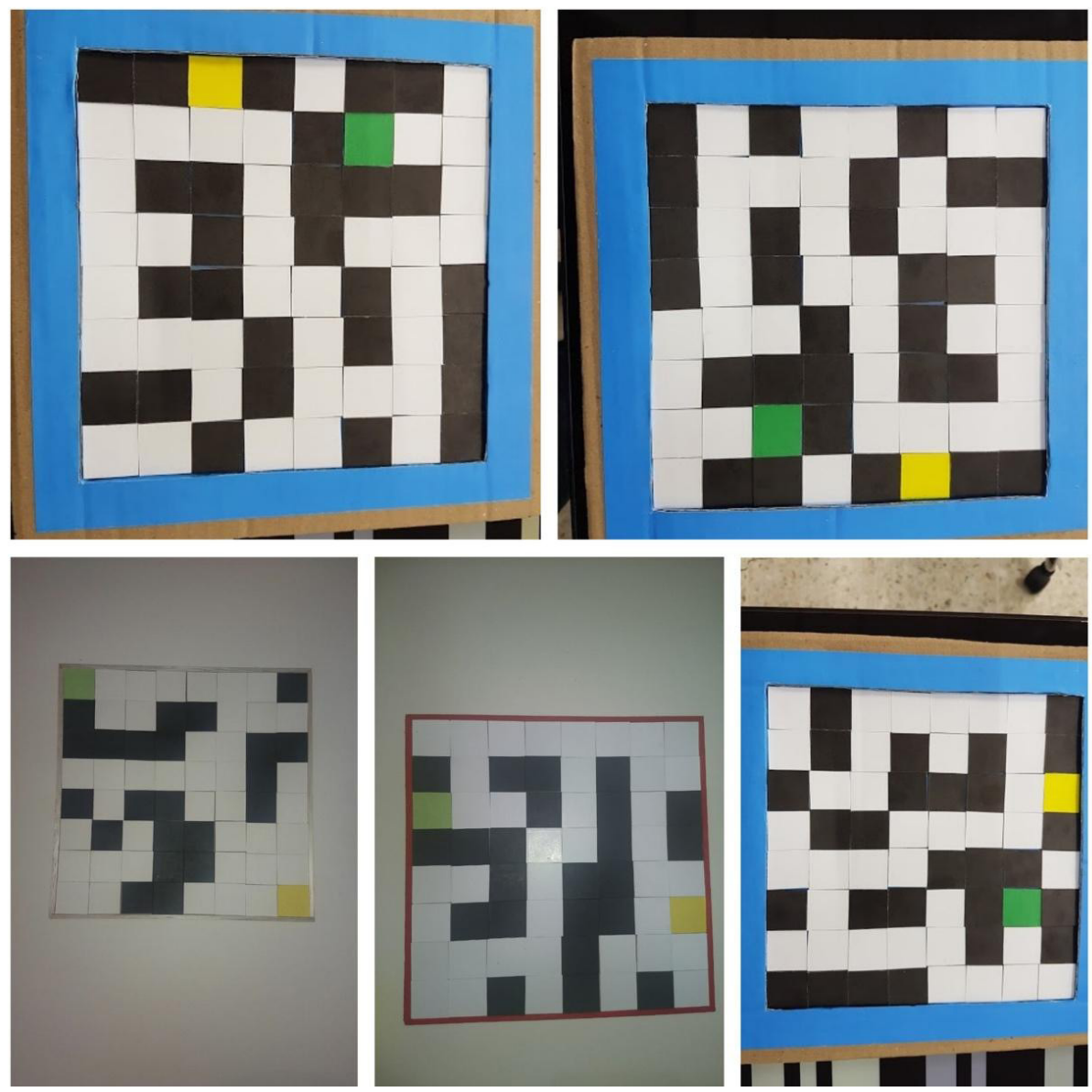

Figura 8. Muestra de las tomas de las imágenes evaluadas Fuente: elaboración propia

Las capturas a más de $70 \mathrm{~cm}$ de distancia presentan dificultades al reconocer una de diez muestras, porque no se identifica el área de segmentación para hacer la evaluación. También las imágenes con capturas torcidas y desenfocadas presentaron dificultades para reconocer la zona de interés. En las imágenes tomadas desde diferentes ángulos al objeto, cenital, picado, normal y contrapicado, a partir de ángulos con desviación mayor a $10^{\circ}$ en relación al ángulo de $90^{\circ}$, el reconocimiento dejaba de ser eficaz.

En imágenes muy oscuras con reflejo de luces o sol, la identificación de las fichas se confunde y no es posible hacer la división del laberinto para su evaluación, se falla entonces en la etapa de extracción de características al no tener una imagen plana. En la figura 9 se denotan algunas de las dificultades presentes en la luminosidad y el ángulo de captura de la imagen para su posterior procesamiento y evaluación. 


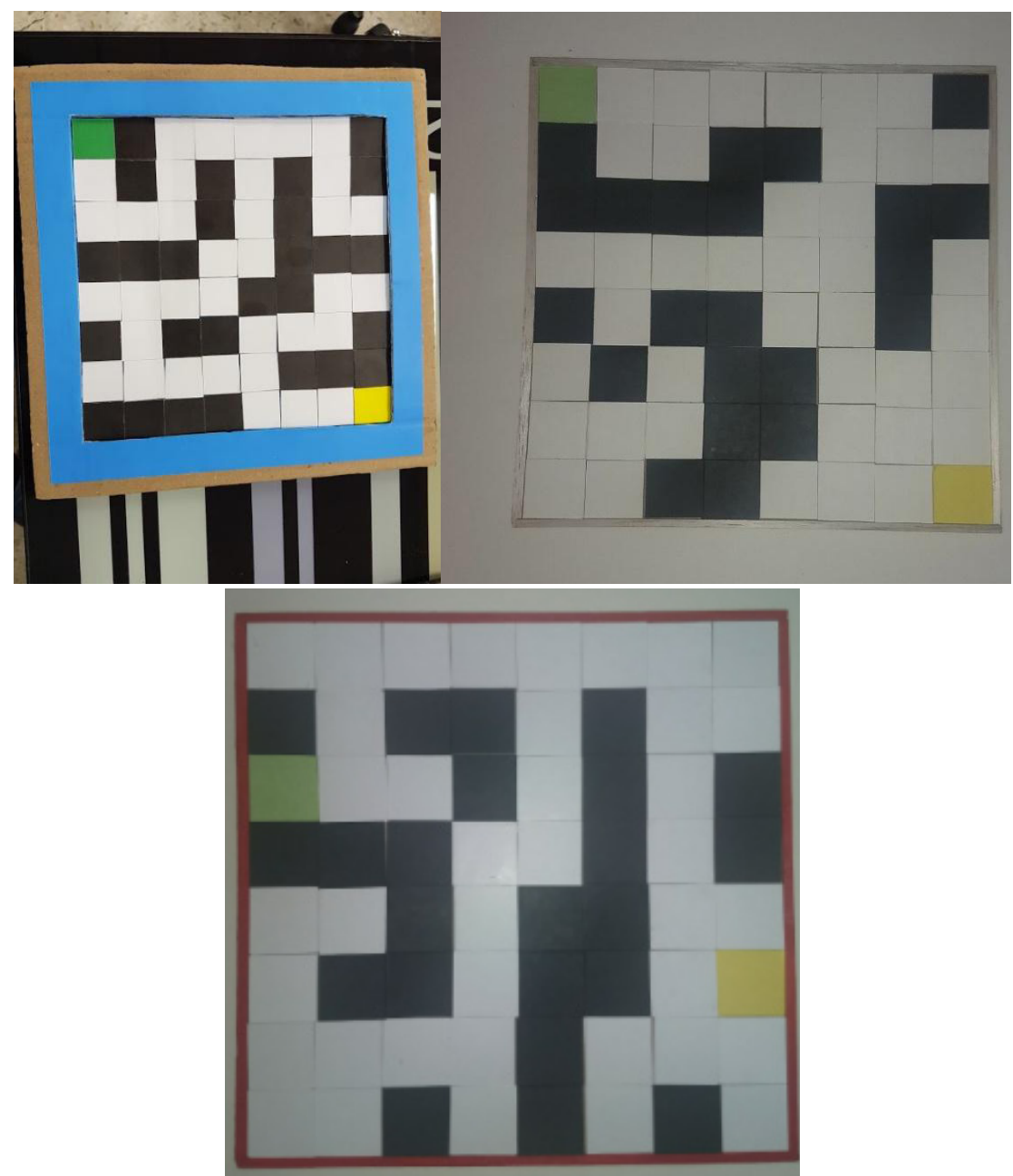

Figura 9. Imágenes oscuras y torcidas Fuente: elaboración propia

Analizando los resultados de las pruebas, se concluye que la identificación es la etapa de más impacto en el procesamiento de imágenes para este proyecto, por lo tanto, para reducir el margen de error del reconocimiento fue necesario depurar los métodos de identificación.

Se hicieron ajustes para optimizar el enfoque de las capturas y se aplicaron filtros que mejoraban e intensificaban las características de cada imagen y el área de interés del laberinto, logrando así reconocer los rasgos de la imagen. Después de realizar estos cambios, se obtuvo un aumento en la efectividad del reconocimiento del $32 \%$, pasando de reconocer 40 de 100 imágenes capturadas a reconocer 72 de 100. 


\section{DISCUSIÓN Y CONCLUSIONES}

Los resultados obtenidos son muy similares, lo que deja en claro que el aplicativo cumple su objetivo de resolver los caminos posibles para solucionar el laberinto, lo que prueba el concepto de ser un compañero de juego para los niños y así puedan desarrollar sus destrezas con un aplicativo que los guie, incentive y direccione para continuar resolviendo los problemas que se le presenten de los laberintos. Cabe recalcar que al utilizarlo con niños, el grado de dificultad para resolver los laberintos es reducida.

Se concluye que la calidad del sensor para capturar la imagen es de vital importancia en este tipo de aplicativos, también el ángulo en el cual se toma la imagen, ya que esta influye en detalles que modifican la información capturada, como definición y cercanía de los objetos.

Durante el desarrollo del ciclo de vida del proyecto se pudieron evidenciar las múltiples aplicaciones que tienen estas dos áreas de la tecnología, lo cual es una invitación a la creatividad e innovación de nuevos grupos de trabajo compuestos por personas con un alto grado de curiosidad.

La posibilidad de integrar lo académico con aplicaciones del mundo real es algo de suma importancia en el crecimiento profesional de los autores, llevar lo aprendido a una oportunidad de investigación, innovación y posible emprendimiento.

Se considera que esta propuesta es innovadora porque dentro de la etapa de recopilación de estado del arte, no se encontró ningún proyecto que propusiera un tablero de laberinto físico como el aquí presentado, ni que se emplearan algoritmos de búsqueda para solucionar laberintos dinámicos.

\section{Trabajos futuros}

Se propone continuar con la mejora de la técnica de reconocimiento de imágenes las fichas del tablero en tiempo real (en video), y complementar la aplicación de inteligencia artificial para obtener resultados más precisos a medida que vaya siendo entrenada.

Realizar todo el procesamiento y la detección en otros dispositivos móviles y multiplataformas, incluso con recursos limitados de sistemas diferentes y así lograr abarcar un mayor segmento de niños que utilizan dispositivos electrónicos a cortas edades, lo que permiten sacar provecho de los sensores y procesadores. 


\section{REFERENCIAS}

[1] F. Siebert, "Un tercio de los niños diagnosticados con déficit atencional son hijos de padres que lo padecieron - Universidad de Chile", [En línea], acceso 23 de marzo 2018; Disponible: http://www.uchile.cl/noticias/131342/origenes-y-pronostico-del-deficit-atencional-en-ninos

[2] C. Felfe y R. Lalive, "Does early child care affect children's development?", J. Public Econ., vol. 159, pp. 33-53, [En línea], acceso marzo 2018; Disponible:https://doi.org/10.1016/j. jpubeco.2018.01.014.

[3] "Juguetes de madera: beneficio de los laberintos". [En línea], acceso 23 marzo 2018; Disponible: https:/juguetutto.com/blog/2016/01/29/por-que-regalar-laberintos-de-madera/

[4] A. Oren, "Children's Use of Board Games in Psychotherapy" Journal of Child Psychotherapy, [En línea], vol 34, pp. 364-383, dec. 2008; Disponible: http://dx.doi. org/10.1080/00754170802472893

[5] J. P. Hinebaugh, A Board Game Education. Maryland, Estados Unidos: R\&L Education, 2009.

[6] J. Begy, "Board Games and the Construction of Cultural Memory", Games Cult., 2015. [En línea]; Disponible: https://doi.org/10.1177\%2F1555412015600066

[7] W.-J. Chou, Y.-P. Chang, y C.-F. Yen, "Boredom proneness and its correlation with Internet addiction and Internet activities in adolescents with attention-deficit/hyperactivity disorder", Kaohsiung J. Med. Sci., [En línea], acceso febrero 2018; Disponible: https://doi.org/10.1016/j. kjms.2018.01.016

[8] C. F. Cortés, J. Giraldo, C. A. Pérez, A. Torres y C. A. Vega, "Móvil con búsqueda de trayectoria en laberinto", Escuela Colombiana de Ingeniería Julio Garavito. December 2008, 2015.

[9] M. O. A. Aqel, A. Issa, M. Khdair, M. ElHabbash, M. AbuBaker, and M. Massoud, "Intelligent Maze Solving Robot Based on Image Processing and Graph Theory Algorithms", in 2017 International Conference on Promising Electronic Technologies (ICPET), 2017, [En línea], pp. 48-53; Disponible: https://doi.org/10.1109/ICPET.2017.15.

[10] "MAZE3D: Un juego de computadora para la estimulación de la orientación espacial / MAZE3D: A computer game for improve spatial orientation | Osorio Josué | RIDE Revista Iberoamericana para la Investigación y el Desarrollo Educativo", [En línea] acceso 24 marzo 2018; Disponible: https://www.ride.org.mx/index.php/RIDE/article/view/147/646https://doi. org/10.23913/ride.v6i11.147.

[11] J. Grompone, El paradigma del laberinto, Montevideo, Uruguay: La Flor del Itapebi, 2011.

[12] C. Jarvis, "Active Launceston launches Active Technology at East Tamar Primary School", The Examiner News, n. ${ }^{\circ}, 2017$, [En línea], acceso 24 marzo 2018; Disponible: https://www. examiner.com.au/story/4641347/technology-used-to-inspire-active-kids/ 
[13] M. Azizinezhad y M. Hashemi, "Technology as a Medium for Applying Constructivist Teaching Methods and Inspiring Kids”, Procedia - Soc. Behav. Sci., [En línea], vol. 28, pp. 862-866, acceso enero 2011; Disponible: https://doi.org/10.1016/j.sbspro.2011.11.158

[14] S. Hojjat, C. Fukuzaki, y T. Sowa, "Maze and Mirror Game Design for Increasing Motivation in Studying Science in Elementary School Students”, 2017, [En línea], pp. 55-64; Disponible: http://dx.doi.org/10.1007/978-3-319-55834-9_7

[15] J. A. Verkhoturova, J. N. Galaguzova, y N. N. Sergeeva, "The Technique of Game Skills Development for Parents Raising Young Children”, Procedia - Soc. Behav. Sci., [En línea], vol. 233, pp. 150-154, acceso octubre 2016; Disponible: https://doi.org/10.1016/j.sbspro.2016.10.174

[16] V. F. Gabdulkhakov, "A Didactic Game Technology", Procedia - Soc. Behav. Sci., [En línea], vol. 233, pp. 170-174, acceso octubre 2016; Disponible: https://doi.org/10.1016/j. sbspro.2016.10.187

[17] C. T. Leondes, Image Processing and Pattern Recognition, San Diego, Estados Unidos: Academic Press, 1998.

[18] S. Jayaraman, Digital Image Processing. Tata McGraw-Hill Education, 2011.

[19] A. Zelinsky, "Learning OpenCV-Computer Vision with the OpenCV Library (Bradski, G.R. et al.; 2008) [On the Shelf]”, IEEE Robot. Autom. Mag., [En línea], vol. 16, n. ${ }^{\circ}$ 3, p. 100, 2009; Disponible: https://doi.org/10.1109/MRA.2009.933612.

[20] S. Kagami, "Utilizing OpenCV for High-Speed Vision Processing”, Adv. Robot., [En línea], vol. 31, n. ${ }^{\circ} 3$, pp. 244-248, 2013; Disponible: https://doi.org/10.7210/jrsj.31.244

[21] N. J. Nilsson, Inteligencia artificial: una nueva sintesis, Madrid, España: Mc Graw Hill, 2001.

[22] A. García, Inteligencia artificial: fundamentos, práctica y aplicaciones. Madrid, España: RC Libros, 2012.

[23] A. Freeman, "Creating Mobile Web Apps", Pro JavaScript for Web Apps, 2012, [En línea], pp. 195-228; Disponible: https://doi.org/10.1007/978-1-4302-4462-2_8 